\title{
STACKING OF BASAL DEBRIS LAYERS WITHOUT BULK FREEZING-ON: ISOTOPIC EVIDENCE FROM WEST GREENLAND
}

\author{
By Peter G. Knight
}

(Department of Geography, University of Keele, Keele, Staffordshire ST5 5BG, England)

\begin{abstract}
This paper tests and falsifies the theory that the development of thick sequences of vertically stacked clean and debris-laden ice layers at the margin of the Greenland ice sheet can be attributed solely to simple freezing-on of material at the bed. Isotopic analysis in $\delta D$ and $\delta^{18} \mathrm{O}$ of ice from the ice-sheet margin near Søndre Strømfjord indicates that the debris-rich and debris-poor elements of the basal sequence have different origins. While the debris bands display isotopic fractionation consistent with a freezing origin, the intercalated clean ice layers do not. The clean ice layers have isotopic values indistinguishable from debris-bearing ice immediately above the debris-band sequence and from unaltered glacier ice, and are entrained by a different process from the debris bands. Debris may be entrained by freezing at the bed, but the development of a vertically stacked sequence of debris bands must be attributed to some other mechanism.
\end{abstract}

\section{INTRODUCTION}

Debris-bearing basal ice is confined to the lowest few metres of temperate glaciers, but in polar and sub-polar glaciers and ice sheets it is often visible at the margin in

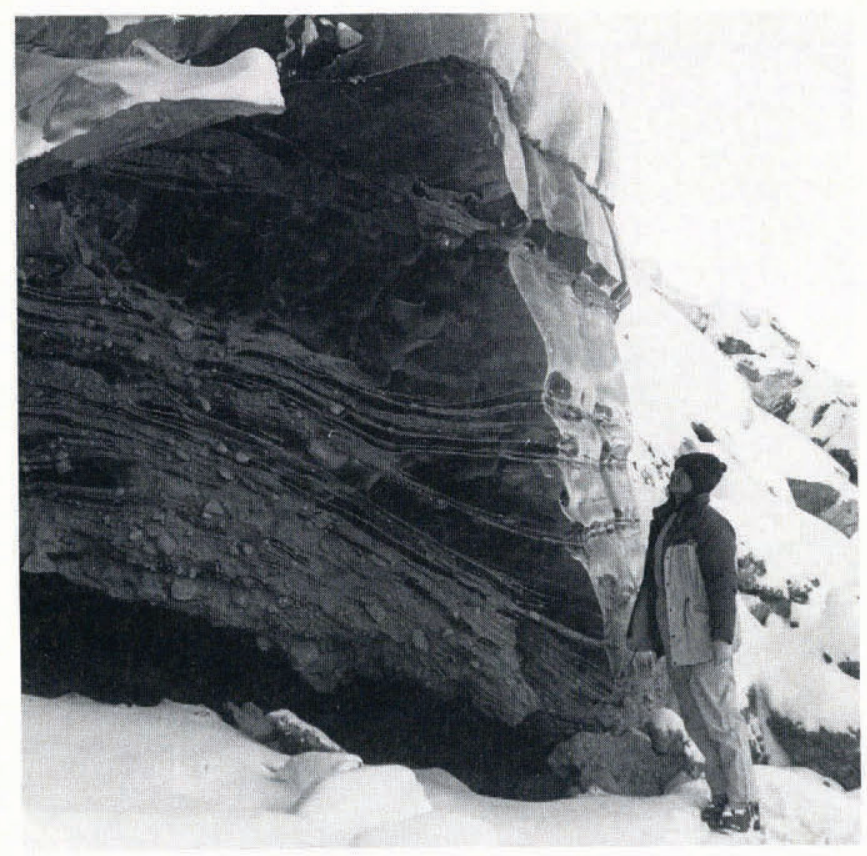

Fig. 1. Photograph showing a sequence of intercalated debris bands and cleaner ice layers at the ice margin. sequences several tens of metres thick. These thick basal sequences of ten comprise a series of distinct debris bands, separated by layers of much cleaner ice (Fig. 1). Various mechanisms have been proposed to explain the development of such vertically stacked sequences but, despite a plethora of theories and counter-theories, few critical tests of specific hypotheses have hitherto been carried out.

Freezing-on of material at the bed is commonly cited to explain both the stacked marginal debris-band sequences and the ice with dispersed debris inclusions which occurs near the bed in the interior and at the margin (Weertman, 1961; Boulton, 1970; Gow and others, 1979; Herron and Langway, 1979). Until recently, it was not possible to demonstrate conclusively whether a particular ice sample was formed by freezing-on at the bed or by normal firnification processes, but developments in co-isotopic analysis (Souchez and Lorrain, 1978; Jouzel and Souchez, 1982; Souchez and Jouzel, 1984; Souchez and De Groote, 1985) have made possible the positive discrimination of refrozen ice in many situations. In this paper, isotopic evidence is used to test the simple freezing-on hypothesis.

\section{Prediction from existing theory}

Weertman (1961) proposed the freezing-on mechanism to explain observed occurrences of debris-band stacking in north Greenland. He suggested that debris is frozen to the bed when the $0^{\circ} \mathrm{C}$ isotherm penetrates into subglacial sediment, and that when the position of the $0^{\circ} \mathrm{C}$ isotherm within the sediment is stable, or where no sediment is available for entrainment, melt water flowing into the freezing zone from the interior of the ice sheet is entrained as a layer of "slightly dirty" ice beneath the frozen-on debris. By repetition of this process, bands of basal debris are lifted above the bed, and separated by layers of cleaner ice.

This freezing-on hypothesis carries the specific prediction that both the debris bands and the intercalated layers of clean ice will be formed of ice frozen from water at a transition from warm- to cold-bed conditions.

\section{The isotopic regelation model}

Jouzel and Souchez (1982) presented a model whereby refrozen ice could be distinguished from firnification (glacier) ice on the basis of its composition in $\delta \mathrm{D}$ and $\delta^{18} \mathrm{O}$. Ice derived from precipitation conforms to the linear relationship $\delta \mathrm{D}=8 \delta^{18} \mathrm{O}+10$ (Craig, 1961; Dansgaard, 1964) such that samples of this ice will lie along a straight line of slope 8 and deuterium excess 10 when plotted on a $8 \mathrm{D}-\delta^{18} \mathrm{O}$ diagram. This is known as the precipitation effect. By contrast, according to the Jouzel and Souchez model, samples of ice formed by refreezing will lie on a different slope, less steep than the parent slope, its precise value depending on the value of the parent water admitted to freeze. This model for a closed system was successfully tested in the laboratory (Souchez and Jouzel, 1984), and subsequently extended to the open system case (Souchez and De Groote, 1985). 


\section{RESULTS}

Samples were collected from two sites at the western margin of the Greenland ice sheet near Søndre Strømf jord, lat. $67^{\circ} 06^{\prime} \mathrm{N}$., long. $50^{\circ} 15^{\prime} \mathrm{W}$. The mean annual temperature in the area is $c .-5^{\circ} \mathrm{C}$. The ice margin is completely frozen for 7 months each winter, but water escapes from the base of the ice sheet throughout the summer, suggesting that at least part of the glacier base is seasonally at the pressure-melting point. Bauer (1968) and Reynaud (1969) reported a maximum downward penetration of temperate ice to about $5 \mathrm{~m}$ below the surface during the summer, and these results are consistent with observations made during the course of the present investigation. At both sites the ice margin takes the form of a steep ramp or cliff, comprising a stacked sequence of intercalated debris bands and ice layers. This pattern is typical of this section of the ice-sheet margin, and is similar to the "Thule-Baffin" type of sequence described by Weertman. The debris bands are $1-10 \mathrm{~cm}$ thick. They occur as solid debris layers with only interstitial ice and as finely interlaminated lenses of ice and debris, merging laterally and vertically between these extremes. The bands are separated by cleaner ice which occurs in layers up to $2 \mathrm{~m}$ thick, and are stacked with the clean-ice layers into a vertical sequence which in places is up to $10 \mathrm{~m}$ thick. The clean-ice layers contain dispersed particles and particle aggregates similar to Weertman's "slightly dirty" ice, frequently concentrated into discontinuous sheets or layers similar to the ice described from the bottom of deep ice cores in Greenland (Herron and Langway, 1979), Devon Island (Koerner and Fisher, 1979), and the Antarctic (Gow and others, 1979).

Sixty samples were analysed in $\delta^{18} \mathrm{O}$, of which 22 were also analysed in $\delta \mathrm{D}$.

\section{Oxygen-isotope results}

The oxygen-isotope results (Fig. 2) discriminate clearly between two distinct sample populations. Samples collected from a $50 \mathrm{~m}$ zone up-glacier from the top debris band are within the range -32.4 to -34.3 in $\delta^{18} \mathrm{O}$. Samples taken from the clean layers in the stacked basal sequence lie within more or less the same range, -32.1 to -34.2 . By contrast, the $\delta^{18} \mathrm{O}$ values for ice in the basal debris bands cover a wider range and are less negative, ranging from -29.4 to -32.5 at site 1 , and from -29.4 to -32.7 at site 2 .

\section{Co-isotopic results}

The co-isotopic results in $\delta \mathrm{D}$ and $\delta^{18} \mathrm{O}$ (Fig. 3) also pick out two distinct groups.

The non-basal ice samples were taken up to $200 \mathrm{~m}$ up-glacier of the top debris band, and hence cover a slightly wider range of values than those shown in Figure 2. They are aligned along a slope of $7.95 \quad(\delta \mathrm{D}=$ $7.958^{18} \mathrm{O}+5.7$, correlation coefficient $=0.99$, standard error of estimate $=3.04 \%$ ). With one exception, the clean basal ice samples are very close to the lower part of this slope. It

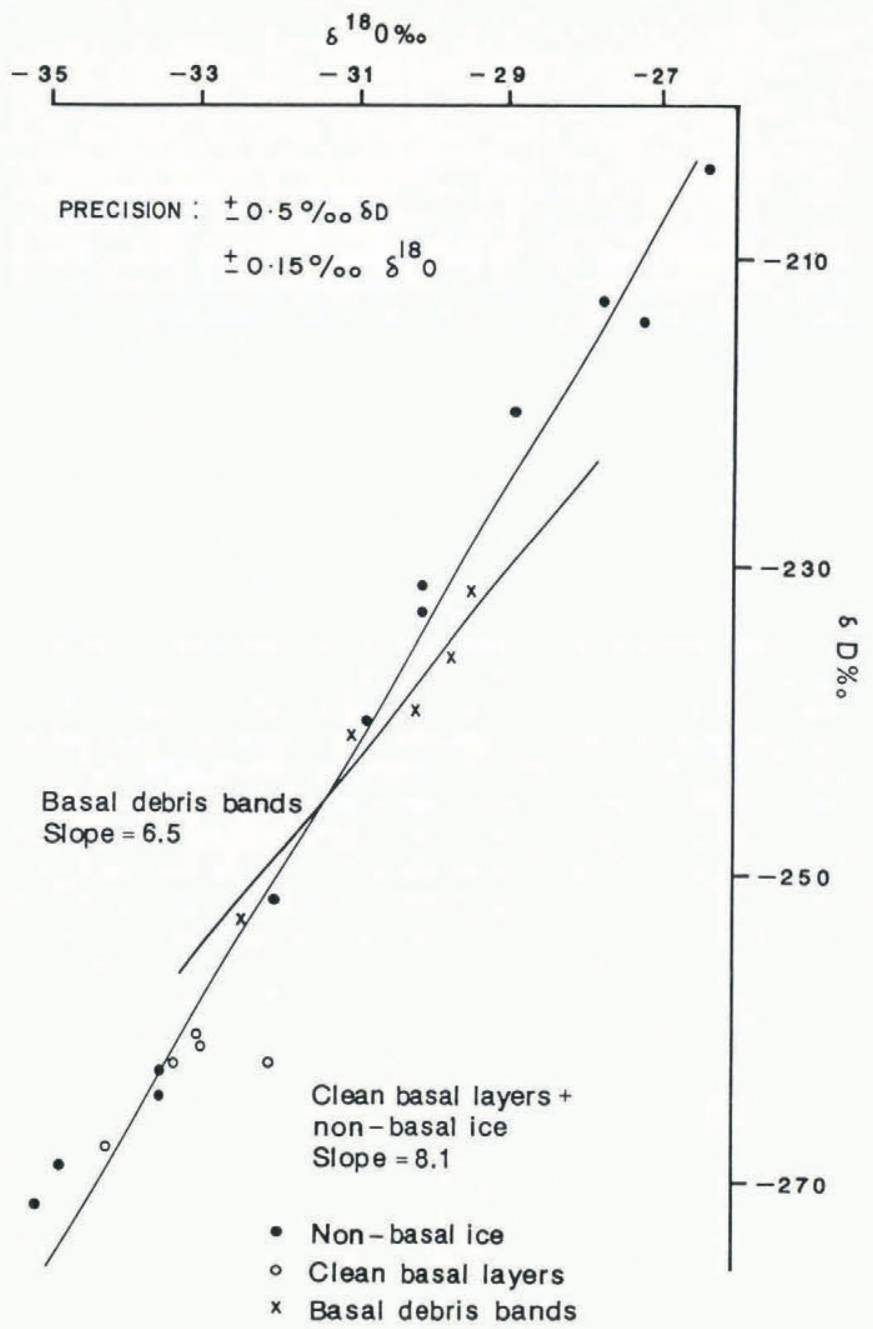

Fig. 3. $\delta D / \delta^{18} O$ diagram for different marginal ice facies up to $220 \mathrm{~m}$ from the margin.

is not possible to plot a reliable slope value for the clean basal ice samples alone, owing to their degree of clustering but, if a regression line is plotted through the clean basal ice and the non-basal ice samples together, it has a slope value of $8.1\left(\delta \mathrm{D}=8.1 \mathrm{\delta}^{18} \mathrm{O}+12.1\right.$, correlation coefficient $=0.98$, standard error of estimate $=3.79 \%$ ). Both possible slopes are indistinguishable from the meteoric slope of unaltered glacier ice.

By contrast, samples taken from the basal debris bands form a second population, and lie along an entirely different slope, with a value of $6.5\left(\delta \mathrm{D}=6.5 \mathrm{\delta}^{18} \mathrm{O}-40.3\right.$, correlation coefficient $=0.98$, standard error of estimate $=$ $1.52 \%)$.

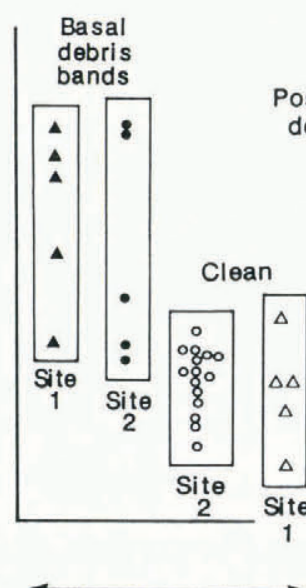

Basal sequence

\section{ISOTOPE SAMPLES}

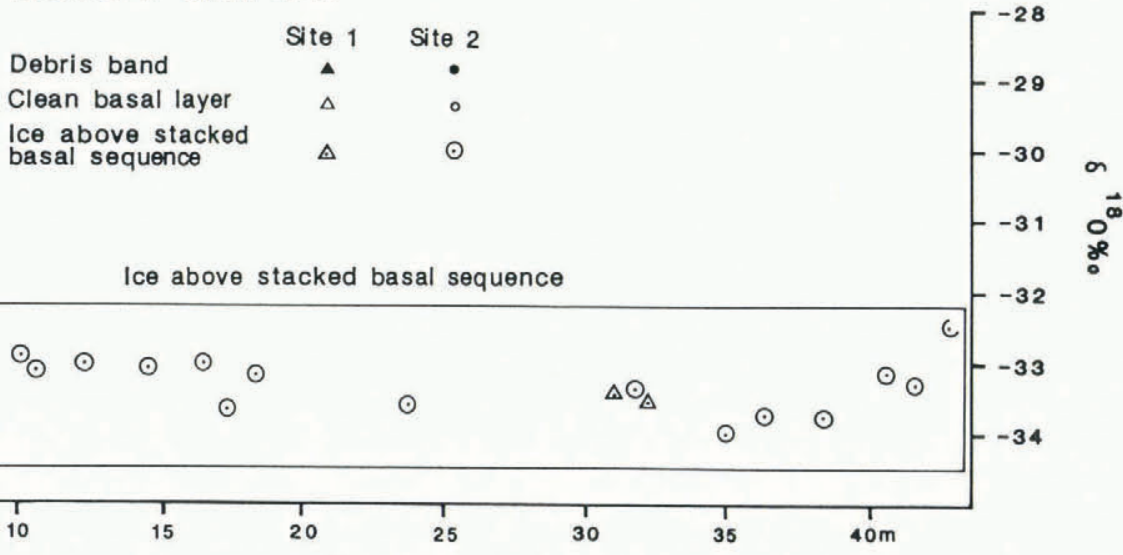

Distance up - glacier from top debris band

Fig. 2. Range of $\delta^{18} \mathrm{O}$ values in different ice facies in the extreme marginal and basal zone. 


\section{Discussion}

The points representing non-basal ice samples in Figure 2 show the range of isotopic values of ice in the marginal zone being brought towards the ice front at present. The similarity of this ice, non-basal ice from further up-glacier (the least negative samples from Figure 3), and clean basal ice, to the meteoric slope (Fig. 3), and the similarity between the range of values in the marginal $50 \mathrm{~m}$ and in the clean basal layers (Fig. 2), suggests a similar origin for these ice groups, and indicates that the clean basal ice has not undergone measurable isotopic fractionation. The clustering of the isotope values of the clean basal layers at the negative end of the meteoric slope representing non-basal glacier ice is consistent with the Reid (1896) model of glacier flow, with the longest travelled, interiorderived ice appearing nearest the bed at the margin. This strengthens the impression that the clean basal ice has not lost the isotopic character of unaltered glacier ice in the same way that the debris bands have done.

The less-negative values in $\delta^{18} \mathrm{O}$ displayed by debrisband samples at both site 1 and site 2 (Fig. 2) suggest isotopic fractionation of the type described by Craig (1961). The isotopic difference between the clean ice and debris bands is consistent with the maximum enrichment value of $3 \%$ in $\delta^{18} \mathrm{O}$ possible for a single freezing event.

The co-isotopic data show a corresponding enrichment in $\delta D$. The difference between the precipitation slope and the $\delta \mathrm{D} / \delta^{18} \mathrm{O}$ regression slope for the debris bands (6.5) also implies that the debris-band ice is not of meteoric origin and has undergone isotopic fractionation of a type consistent with freezing-on at the glacier bed. However, the implications of the co-isotopic results must be treated with caution, as they are based on only five debris-band samples, and the significance of the difference between these samples and the precipitation slope is therefore questionable.

If the "slightly dirty" ice between the debris bands in the basal sequence does have a basal origin, as suggested by the presence of dispersed debris, then the manner of its entrainment must be different from that of the debris bands, in that the clean layers show no evidence of fractionation. Lawson (1979) attributed this "dispersed facies" ice with debris clots to localized pressure melting and refreezing at a small scale and without water loss, and hence without fractionation. Sugden and others (1987) attributed ice with dispersed clots above the marginal debris sequence in West Greenland to a similar process, and there is no evidence available as yet to refute this hypothesis for the cleaner layers between debris bands in the basal sequence.

That the range in $\delta^{18} \mathrm{O}$ of clean basal ice layers is greater than the corresponding range for ice in the $50 \mathrm{~m}$ or so above the debris-band sequence probably reflects variations in the isotopic composition of ice reaching the margin at different times in the recent past. The range would be expected to be greater in a narrow zone at the margin than in a somewhat wider zone in the interior if compression at the margin results in the stacking of ice by the overthrusting of fresh ice from up-glacier. If the $50 \mathrm{~m}$ section shown in Figure 2 then represented a single cohort of ice, the clean layers in the stacked sequence would represent sections from a number of different recently arrived cohorts, each with a slightly different isotopic range.

\section{CONCLUSIONS}

Debris bands in the basal ice layers at the margin of the Greenland ice sheet near Søndre Strømfjord display isotopic fractionation effects typical of refrozen ice, but intercalated clean-ice layers in the stacked marginal sequence do not clearly indicate such effects. It is possible that this is due to the smaller data set available for the clean ice but, whether or not the intercalated clean-ice layers are entrained at the bed, it is clear that the two components of the basal sequence thus have different origins. The isotopic signature of the clean layers is similar to that of ice above the stacked debris-band series, the origin of which remains uncertain.

While this evidence supports the proposition that the material in the debris bands is entrained by a freezing process, Weertman's (1961) hypothesis that the debris bands are stacked into a vertical sequence by the bulk freezing-on of both clean and dirty ice at the bed cannot be sustained at this site. The origin of the clean-ice layers and the stacking of the sequence must be explained by some other mechanism, which is the subject of continuing investigation.

\section{ACKNOWLEDGEMENTS}

This work was partly funded by a U.K. Natural Environment Research Council studentship while the author was based at the University of Aberdeen. Isotopic analyses were carried out by W. Dansgaard in Copenhagen, and by J. Jouzel in Paris. The author wishes to thank D. Sugden, R. Souchez, R. Lorrain, and J.-L. Tison for valuable discussion, and S. Miller and J. Friez for additional help in the field. K.H. Jørgensen deserves special thanks for her endless hospitality and assistance both in Denmark and in Greenland.

\section{REFERENCES}

Bauer, A. 1968. Missions aériennes de reconnaissance au Groenland 1957-1958. Medd. Gronl., 173(3).

Boulton, G.S. 1970. On the origin and transport of englacial debris in Svalbard glaciers. J. Glaciol., 9(56), 213-229.

Craig, H. 1961. Isotopic variations in meteoric waters. Science, 133, 1702-1703.

Dansgaard, W. 1964. Stable isotopes in precipitation. Tellus, 16(4), 436-468.

Gow, A.J., S. Epstein, and W. Sheehy. 1979. On the origin of stratified debris in ice cores from the bottom of the Antarctic ice sheet. J. Glaciol., 23(89), 185-192.

Herron, S. and C.C. Langway, jr. 1979. The debris-laden ice at the bottom of the Greenland ice sheet. J. Glaciol., 23(89), 193-207.

Jouzel, J. and R.A. Souchez. 1982. Melting-refreezing at the glacier sole and the isotopic composition of the ice. $J$. Glaciol., 28(98), 35-42.

Koerner, R.M. and D.A. Fisher. 1979. Discontinuous flow, ice texture and dirt content in the basal layers of the Devon Island ice cap. J. Glaciol., 23(89), 209-222.

Lawson, D.E. 1979. Sedimentological analysis of the western terminus of the Matanuska Glacier, Alaska. CRREL Rep. 79-9.

Reid, H.F. 1896. The mechanics of glaciers. J. Geol., 4, 912-928.

Renaud, A. 1969. Etudes physiques et chimiques sur la glace de l'indlandsis du Groenland 1959. Medd. Gronl., 177(2).

Souchez, R.A. and J.M. de Groote. 1985. $8 D-\delta^{18} \mathrm{O}$ relationships in ice formed by subglacial freezing: paleoclimatic implications. J. Glaciol., 31(109), 229-232.

Souchez, R.A. and J. Jouzel. 1984. On the isotopic composition in $\delta D$ and $\delta^{18} \mathrm{O}$ of water and ice during freezing. J. Glaciol., 30(106), 369-372.

Souchez, R.A. and R.D. Lorrain. 1978. Origin of the basal ice layer from Alpine glaciers indicated by its chemistry. J. Glaciol., 20(83), 319-328.

Sugden, D.E., and 6 others. 1987. Evidence for two zones of debris beneath the Greenland ice sheet. Nature, 328(6127), 238-241.

Weertman, J. 1961. Mechanism for the formation of inner moraines found near the edge of cold ice caps and ice sheets. J. Glaciol., 3(30), 965-978. 